\title{
A Technical and Contextual Analysis of Scenography Through Sculptural Reproduction: Hofman and Tröster's Hamlets
}

\author{
Dan Matthews
}

\begin{abstract}
Vlastislav Hofman's Hamlet at the National Theatre in 1926 and František Tröster's Hamlet at the Vinohrady Theatre in 1941 are undeniably different interpretations of one of Shakespeare's superlative plays. They are notable as works that illustrate a slight change in aesthetic for the designers, with Hofman moving away from his roots in Czech Cubism and Tröster showing his mastery of staging while letting the scenery take on an ethereal, minimal quality.

My research has focused on recreating the sets to scale in a format that can be viewed in a gallery setting. This paper seeks to frame each example in its historical context, give an account of the transition from initial rendered ideas to what ended up on the stage, and document the process of constructing the models with a focus on permanence and attracting the interest of gallery-goers while staying true to the scenographer's work.
\end{abstract}

\section{Keywords}

Vlastislav Hofman, František Tröster, Hamlet, scenography, maquette, model, Shakespeare, Vinohrady Theatre, National Theatre, Prague, reconstruction

Submitted as part of the Czech and Slovak Scenography for Shakespeare Symposium Columbus Museum of Art March 3-4, 2017. 
The designs by Vlastislav Hofman for Hamlet at the National Theatre in 1926 and František Tröster's for the same play at the Vinohrady Theatre in 1941 are undeniably different visual interpretations of the text. They are notable as works that illustrate a slight change in aesthetic for the designers, with Hofman moving away from his roots in Czech Cubism and Tröster showing his mastery of staging with the scenery taking on an ethereal, minimal quality. My practice-based research has focused on recreating the sets to scale as model boxes, in a format that can be viewed in a gallery setting.

Through the process of gathering production photos and copies of renderings it became apparent that what was intended in the earlier and arguably more interesting renderings was sometimes quite different than what ended up on stage. The inevitability of budget and time constraints, facilitation of scene changes, and, in Hofman's case, structural impossibilities, likely required some compromise, as is the nature of theatre. I made the decision to recreate the sets as rendered, not as built, to be complementary to the initial ideas of Hofman and Tröster. This paper seeks to frame each example in its historical context, give an account of the transition from initial rendered ideas to what ended up on the stage, and document the process of constructing the models with a focus on permanence and attracting the interest of gallery-goers while staying true to the scenographer's work.

In Hofman's Hamlet, he creates a world that mostly exists in a black void, letting the architectural elements take prominence. One can still identify his roots as a Czech Cubist in some of the elements, especially in the court scenes. Art Deco motifs make their way into the scenery as well. This is perhaps because of Hofman's beginnings as a modernist designer and the somewhat heady, Bohemian, artistic blooming that occurred between the wars. Conversely, Hofman's interpretations of the church and graveyard scenes take on the quality of a war memorial and are more reflective of the turmoil within Hamlet. The church is an example of a stripped down aesthetic, with simple yet effective uses of line and shape and no embellishment, other than the plain cross. In it, Hofman creates a dynamic structure that functions just as easily for large crowd scenes as it does for soliloquies. We see him using the space less as a decorative designer and more as a theatre artist. In 1926 the confusing, long-lasting after-effects of World War I were taking their toll, just as Czechoslovakia was finding its footing as a nation. The rationality of modern society was certainly in question. While many struggled to move on and forget the horror of war in favour of the happy-go-lucky, flapper attitude embraced by America, others were so affected by the war that everything was now put into question, even existence. Hamlet was, in some ways, the perfect play for the times. Hamlet is having his own existential crisis in dealing with the irrationality of his father's deplorable murder while the rest of his family and the court move on with seeming forgiveness or complicity. Hofman's church illustrates this quality better than any other scene in the play, which is partly why I selected it for reproduction. I chose to use his white-on-black sketch of the church as my source material. The angles and proportions of the church wall in this rendering are the most interesting to me, yet these same qualities, when built in three dimen- 


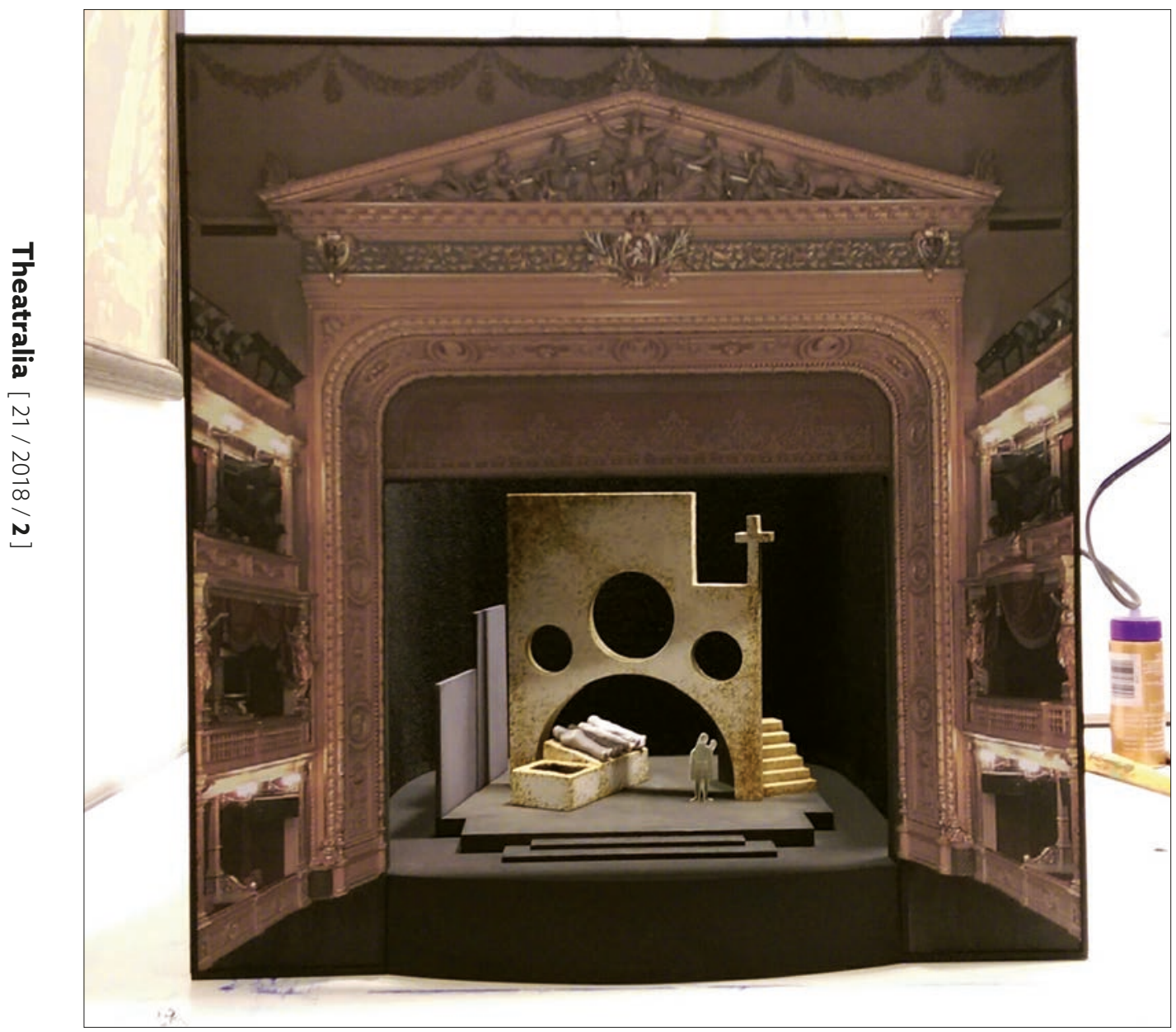

Fig. 1: The reproduction of Hofman's Hamlet at the Vinohrady Theatre.

sions, led to difficulties in trying to facilitate use of the high, round windows which were a necessary aspect of the church scenes.

In studying Tröster's plentiful sketches and renderings for Hamlet we see the main scenic feature develop from a jagged hole in a black background revealing a blue sky to a sweeping, curved wall with a smooth parabolic cut-out, revealing the same sky. Opening the back wall at the top allows the sky to continue out of the audience's point of view, seemingly infinitely. This is conceivably why Tröster chose to continue with this motif. In František Tröster: Artist of Light and Space, Vlasta Koubská expresses a similar position:

The shape of the parabola in itself concentrated several new meanings. It symbolized the 'valley of treachery' or the closed ravine from which there is no escape, but at the same time the open and hopeful space of the future (KOUBSKÁ 2001: 81). 


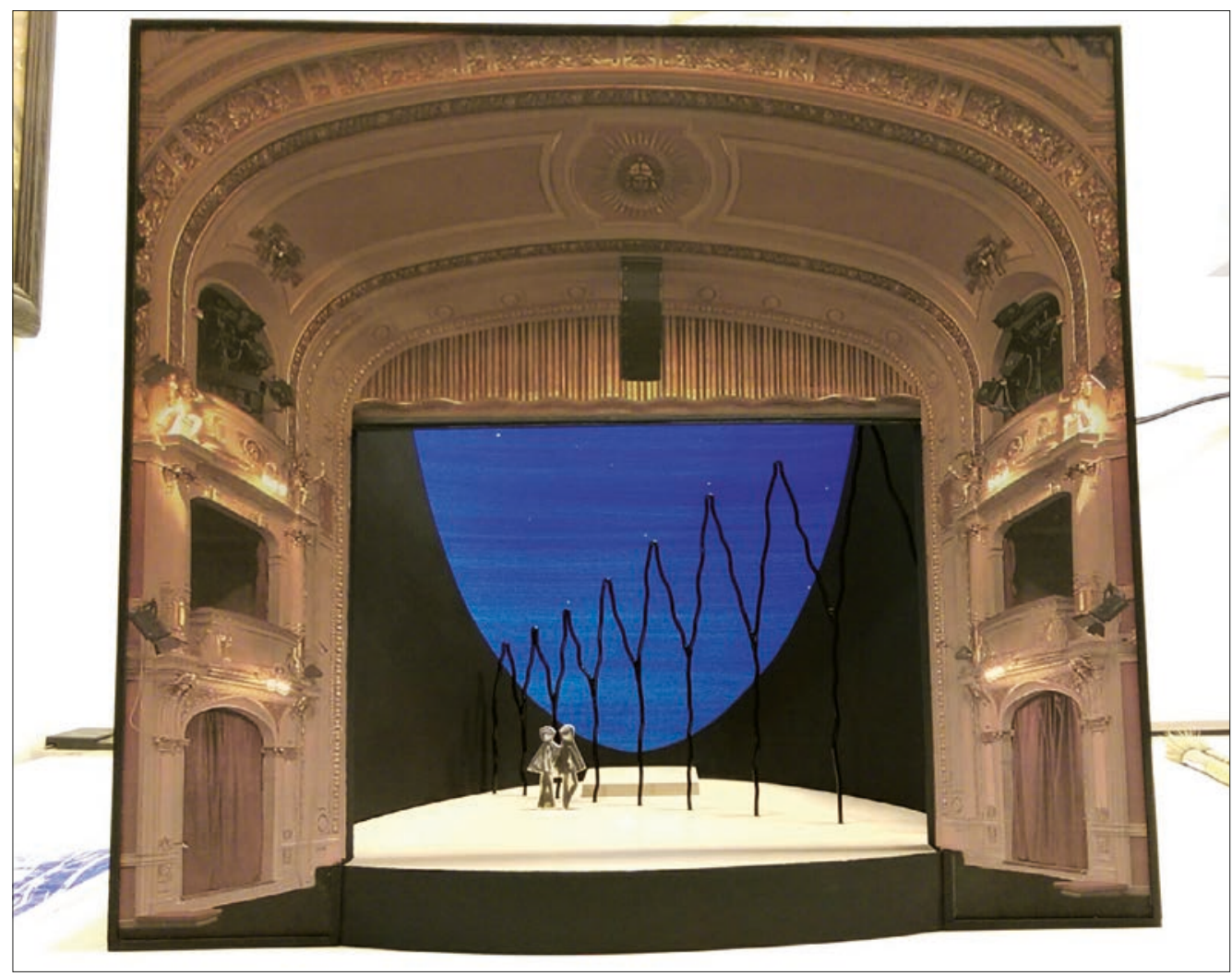

Fig. 2: The reproduction of Troster's Hamlet at the National Theatre.

In 1941 Central Europe was dealing with an unknown future. People were trying to hold onto hope, but with a figuratively restricted view of their futures. Tröster's infinite sky, with a literally restricted view framed by blackness, echoes these sentiments. Tröster utilised his inverted parabola to hide curved staircases, leading up from the bottom of the arch. It is undeniable that he was adept at using all three dimensions of the stage space, and the use of these staircases in some of the crowd scenes exemplifies his brilliance. This dynamic effect was powerfully rendered in Tröster's design drawings but the same scale was not achievable on stage. As seen in production photographs, the crowd scenes dilute the sweeping, ethereal nature of the scenography. Another powerful image from Tröster's drawings are the rows of twisted, black arches that appear in different, diagonal orientations on the stage. This minimal representation of architecture seems to tower over the stage and audience through the use of forced perspective and bright, diagonal back light. The black, skeletal forms are reminiscent of burnt or bombed-out structures. The Czechs would have long been familiar with the devastation in Europe by modern warfare through imagery or first-hand experience, and perhaps this was a statement directed against the German occupation. The visual metaphors created by the arches could have resonated with audiences, but whether or not Tröster 


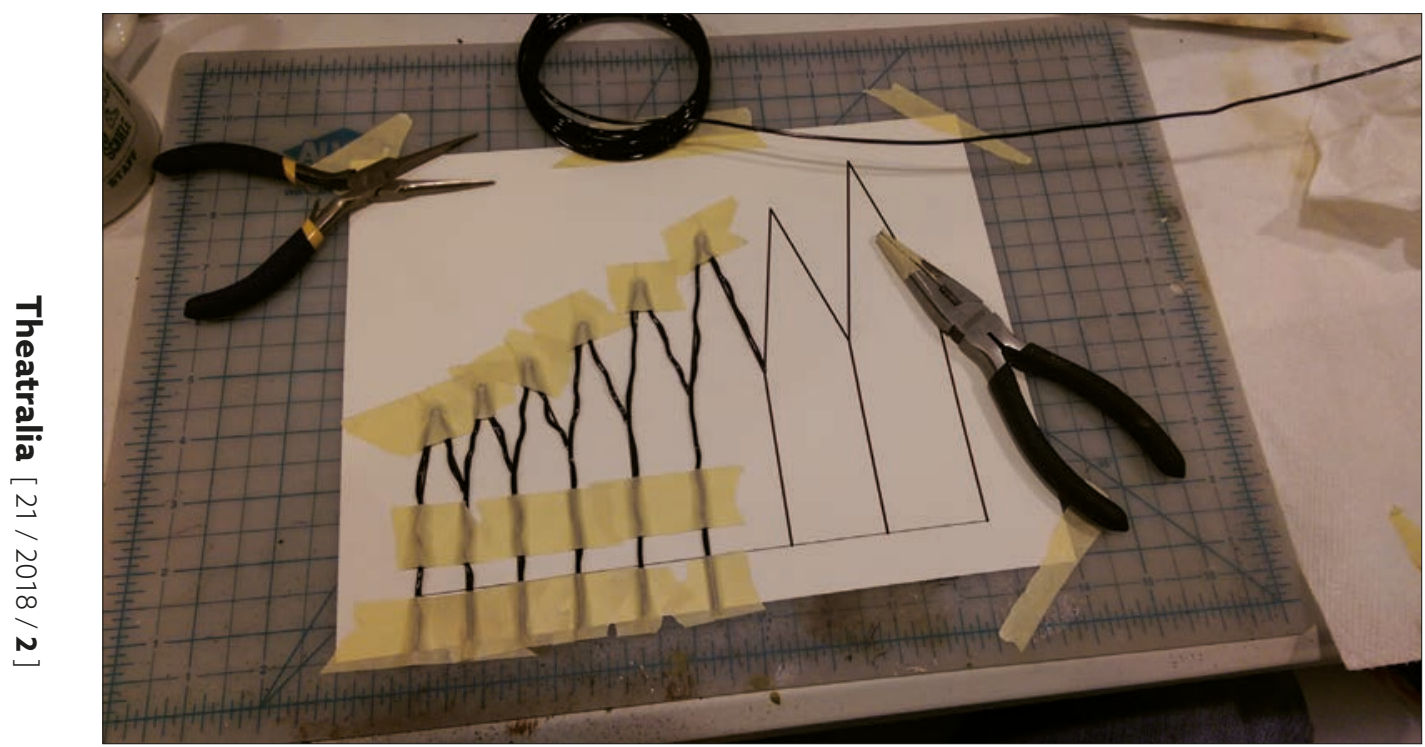

Fig. 3: Bending wire on a template to form the descending arches for the Troster model.

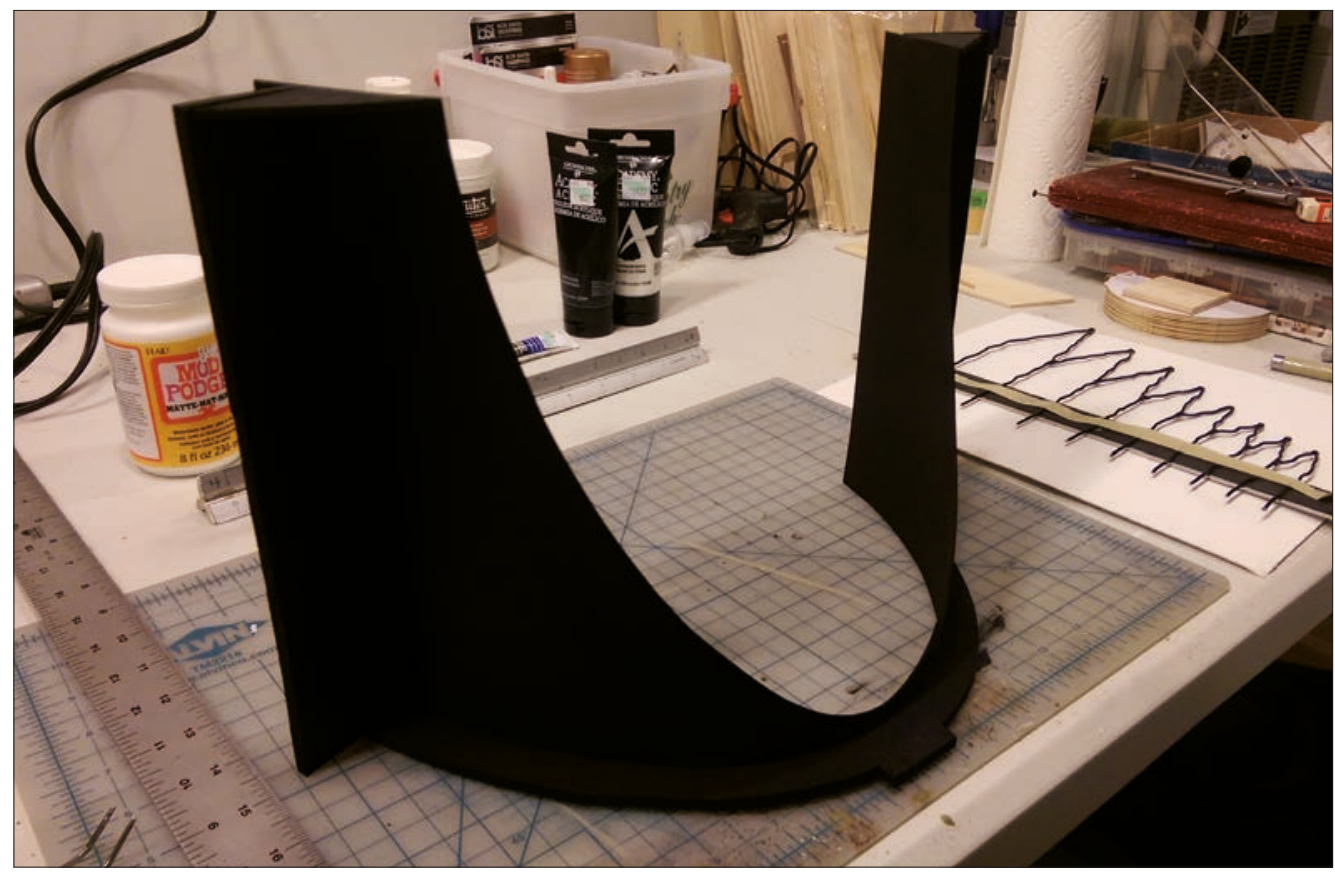

Fig. 4: The Troster model's compound, inverted arch viewed from behind. 


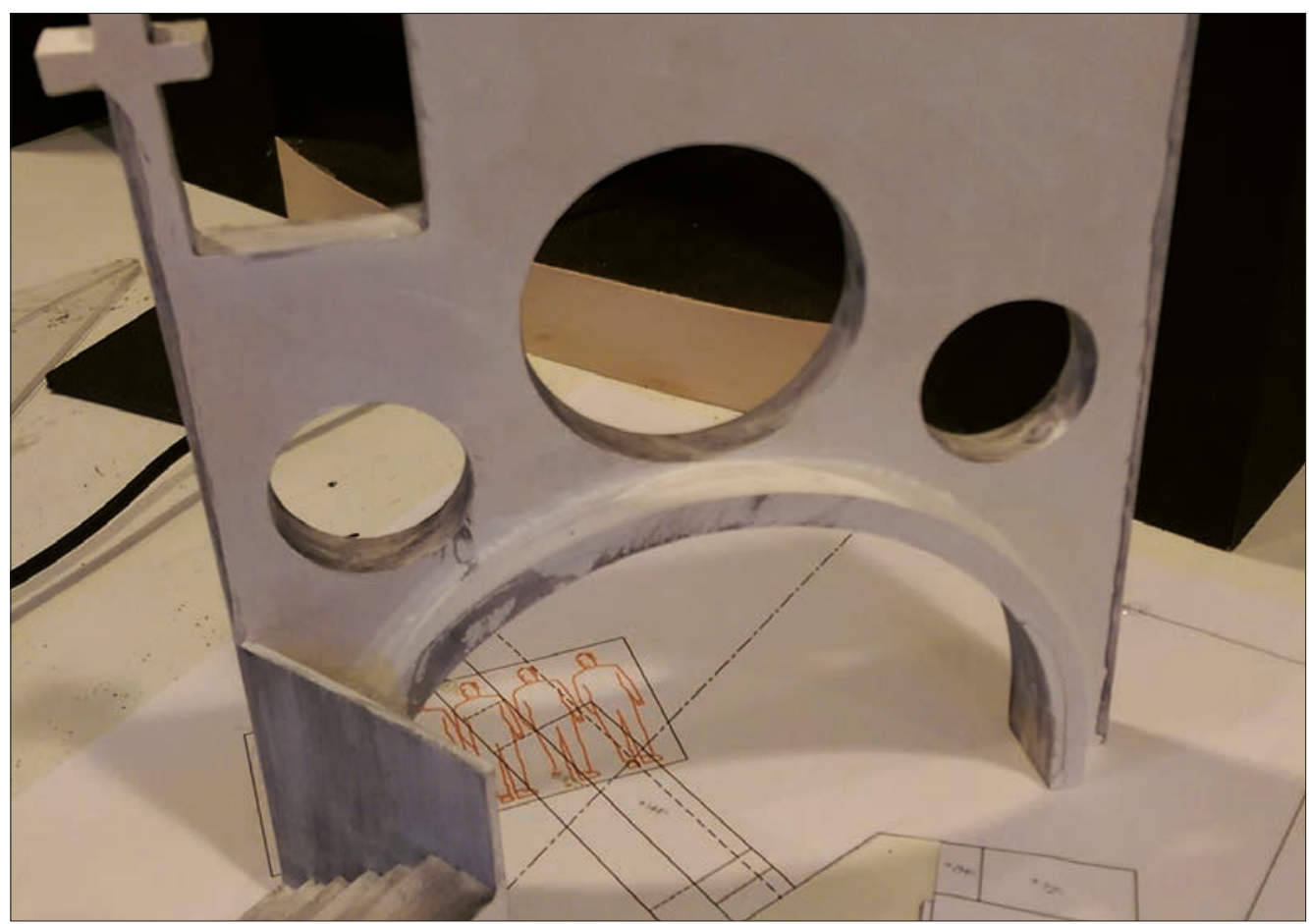

Fig. 5: The Hofman model church structure viewed from behind.

intended this correlation is unclear. To alter the space from scene to scene he used large swaths of sheer fabric flown in from the grid. These were similar to ship sails, which could have been a nod to sea voyages featuring prominently in Hamlet's plot. The sails broke the shape of the parabola allowing for greater change from location to location, but the infinite, yet restricted sky is always a feature. I chose a fairly bare scene for reproduction, for which there are several different renderings. In my opinion, this location best illustrates the most prominent features of the design: the sky, parabola, and arches.

The first step in constructing the models was to build the boxes that would house the scenery. The dimensions for each space were attained from the Theatre Architecture in Central Europe Database: TACE. ${ }^{1}$ I created AutoCAD drawings for each theatre as well as plan and elevation drawings for each design, using renderings and sketches from the Czech National Museum as references. In order to frame the scenery with a representation of the theatre architecture I planned to attach printouts of the proscenium and surrounding structures on the front of the model boxes. I found these images on each theatre's respective websites, captured from virtual tours (Národni divadlo and Divadlo na Vinohradech). The printouts needed extensive work to straighten the perspective, raise the curtains to the appropriate height, and make sure they would be to scale.

1 See https://www.theatre-architecture.eu/. 
This involved use of both Photoshop and AutoCAD. So as to not damage the printouts I waited until the model scenery was installed to attach them. This involved extensive masking to protect the work because spray adhesive was the best option (my tests with découpage paste resulted in wrinkled, smudged paper).

Hofman's church wall, platforming, stairs, and return walls were all made from laminated $1 / 8$ " and 1/4" plywood, shaped with a table saw, band saw, and hole saws. This was more permanent and sturdy than illustration board, which is the standard for light weight, cost-effective theatrical models. Also, because of the thickness of the layered plywood, I didn't have to build reveals for the inner edges of the round windows and arch. While arranging the pieces in three dimensions I found it impossible to reproduce exactly Hofman's white-on-black sketch. I found a way to approximate what was drawn, but building the platform that should have existed behind the church wall, allowing actors to appear in the round windows, and attaching the stairs to that platform was unworkable. This probably led Hofman to flatten the angle of the church wall to the audience, widen it, and make the windows smaller in relation to the wall. The grave and bier were carved from basswood, and the bodies were purchased from a model train supplier. They were moulded and painted to look contemporary, but once they were painted and shrouded in dyed pantyhose, they made decent likenesses. To recreate the curved, black background seen in Hofman's sketch, I used felt paper which is dark black and non-reflective. I built a curved frame out of plywood and basswood to hold the paper taught. I had to use hot glue because nothing else would bond to the felt paper without bleeding through to the front. Even then the hot glue could shrink the felt if I wasn't careful. To determine colours and paint techniques I used production photos and my memory of viewing the original model in the Czech National Museum archives at Terezín. I used gesso to create a light plaster-like texture and painted it to look aged and dirty. I used dark grey on the return walls to shift focus to the church structure. These walls don't exist in the production photographs I have seen. For the figure of Hamlet, I used Hofman's costume design sketch, shrunken to scale and laminated to illustration board.

The most difficult part of building the Tröster model was figuring out the curved wall and parabolic cut-out. My chosen method involved taping Bristol board to the floor of the model box in a curve that matched what was shown in the renderings. I then used a pencil to sketch in the shape of the parabola. My lines were not symmetrical or smooth so I used them as a reference to create a series of stencils to cut out the now well-formed parabola. I glued this to a plywood base matching the curve of the wall and painted it flat black. I omitted the stairs because they aren't visible from the audience's point of view and not used in my chosen scene. In Tröster's renderings, the black arches seem to have dimension because of the reflective highlights, but in the production photographs it appears as though they were flat plywood or fabric cut-outs with the highlights painted in. I chose to re-create them with black, glossy, aluminium wire which would more closely approximate the renderings. Using a printout from my AutoCAD elevations, I shaped the wire arches over the drawing using masking tape to hold the pieces down as I attached the joints with epoxy. This involved careful cutting 
and filing of each piece of wire. The wires were intentionally left long, so they could be embedded through the model box floor and epoxied from underneath. I taped them to a straightedge to keep them aligned while being sprayed with black lacquer. The straightedge also allowed me to embed the wires in the floor at the correct height. The holes in the floor were drilled in a straight line, using another AutoCAD printout as a guide. Though the actual arches would have been rigged from above, embedding the model pieces in the floor was the only way to ensure they would stand up straight and be durable. Tröster's sky was probably accomplished with coloured light on a curved cyclorama, which would not have been uncommon to find in a theatre like the Vinohrady. The construction was similar to what I had done for the black background in Hofman's model, but with flat spots and tighter curves. Because the illustration board used for the painted cyclorama was much stiffer than the felt paper used for Hofman's background, I had to use a series of clamps and thick super glue with a quick-set agent to ensure a proper bond. The figures in the model are from one of Tröster's earlier renderings. It is unclear which characters they are meant to represent, but I felt it was important to somehow incorporate his style into the scale figures.

I would like to emphasise some questions that came to mind while working with these models for over eighty hours. Does scenography lose its artistic merit once it is taken out of its context? If we are not witnessing the show while sitting in a dark theatre can we truly appreciate the scenographer's vision? Can we reassign that merit by setting the work in a gallery, or is the value inherent? What if the scenographer's hands never touched it? Having seen the reactions of both casual and educated viewers of several different scenography exhibitions, I believe that samples of notable scenographic work can stand alone as art. However, much of the work's power is lost when we are not seeing it in performance, with the visceral reactions that the elements of live theatre can bring. When high quality production photographs or videos are exhibited, we are still only witnessing something analogous to the production. In addition, we are often viewing the scenographer's process and not the final result. Practitioners of theatre may find this difference to be most notable. Through the process of recreating these designs, I found that what was originally conceived was often better than what could be achieved on stage. As is apparent from the forced perspective of Hofman's original church renderings or the impossibility of scale in Tröster's crowd scene sketches, the need for compromise in theatrical design is part of the process. This inevitably leads to challenges, but it often shows us new, interesting options. In building these models I encountered similar challenges in trying to extrapolate three-dimensional structures from sketches and drawings. This gave me insight into the scenographers' process and the inevitable changes that were made along the way. Through this process of recreation, we can more easily identify why some initial design ideas changed, and by identifying common elements, we can see how the scenographer's priorities remain in place from sketch to stage. 


\section{Bibliography}

Divadlo na Vinohradech [Vinohrady Theatre Virtual Tour]. 2017 [online]. [accessed on December 2006]. Available online at http://www.divadlonavinohradech.com/content/files/virtualniprohlidka/index.hrml.

KOUBSKÁ, Vlasta. 2007. František Tröster: Artist of Light and Space. Prague: Obecní dům, 2007.

Národni divadlo [National Theatre Virtual Tour]. 2017 [online]. [accessed on December 2006]. Available online at http://www.narodni-divadlo.cz/panorama/ND_vsechny_eng/.

Theatre Architecture in Central Europe Database: TACE 2017 [online]. [accessed on November 2006]. Available online at http://www.theatre-architecture.eu/db.html.

\section{Dan Matthews}

Assistant Professor at Ohio State-Lima Regional Faculty,

Ohio, United States

matthews.198@osu.edu

Dan Matthews started his theatre career in his home town of Rock Springs, Wyoming where he earned an Associate of Fine Arts degree in Musical Theatre from Western Wyoming Community College. While continuing his theatre studies at the University of Northern Colorado he began exploring the Design and Technology fields; this led him to The Ohio State University, where in 2006, he received an MFA in Theatre Arts with an emphasis in Scenic and Lighting Design. After three years as the Faculty Technical Director for the Kansas State University Theatre Department, he relocated to Chicago, IL to pursue a freelance career in Design and Technical Direction. He found a niche with Chicago Shakespeare Theater as a House Carpenter and Tour Technical Director. In his four years there he helped bring professional Shakespeare productions to schools all over Chicago, northwest Indiana, Wisconsin, and western Illinois. As an Assistant Professor for the Ohio State Lima Department of Theatre Dan fulfills the roles of Scenic Designer, Lighting Designer, Technical Director, and Production Manager. His Jack-of-All-Trades approach to theatre has prepared him well for this multifaceted position. 